\title{
Operationalising the Concept of Basic Needs
}

\author{
RICHARD J. SZAL * \\ If an urn does not have the characteristics of an urn, how can we call it an urn. \\ Confucius: The Sayings of Confucius
}

\begin{abstract}
Much rhetoric has appeared over the last few years about the desirability of the basic-needs approach to development planning. The basic-needs approach, however, has remained more of a proclamation of good intentions than a strategy for development. Operationalising it poses certain difficulties. In this article, two novel ways of transforming the basic-needs philosophy into concrete policies and strategies are presented. The discussion consists of explanations of planning tools entitled basic-needs activities and product path analysis. Finally, some brief comments are offered on the use of popular participation in a basic-needs strategy and possible trade-offs between basic-needs satisfaction and growth.
\end{abstract}

The continuing debate over the optimal way to raise the employment and income earning opportunities of the poor, particularly in developing countries, culminated in the World Employment Conference of the International Labour Organisation in 1976 which urged that

Strategies and national development plans and policies should include explicitly as a priority objective the promotion of employment and the satisfaction of basic needs of each country's population [2, para. 13].

Translating this rather open proclamation into action poses difficulties, however. Certain fundamental questions arise as soon as one considers the implementation of a basic-needs strategy. What are basic needs? How is a basic-needs strategy different from those which have been pursued in the past? This is not the place to go into a full and detailed discussion of the philosophy behind the concept of basic needs, but a few clarifications can be given.

The basic-needs approach should be viewed as an organising concept. Past development strategies have been a type of top-down approach in the sense that macro-economic goals for growth were set and then the benefits were to filter down to the population through nutrition, education, health and housing programmes,

*The author is associated with the Rural Development Policies Branch, Employment and Development Department, ILO, Geneva. 
among others. What the World Employment Conference emphasised is that such an approach hasn't worked to solve the poverty problem, and thus, it cannot be expected to succeed in the future. For many reasons the link between the macro goals and the social programmes has not materialised, or if it has, the benefits have not flowed to the intended recipients. The basic-needs approach advocates a more micro view to planning in that the social programmes are designed and carried out, and they are designed in such a way as to lead to economic growth. Growth is a result of socially oriented programmes and not the reverse.

There is not one universal set of basic needs. The definition of what constitutes them will vary from one country to another, and to the extent possible, the people themselves should be the ones to define their needs. Possible candidates include food, clothing, shelter, education, health, water and sanitation, and transportation. Some would include non-physical items in the list, such as employment and participation in the decisions which affect one's life. Just as there is not one uni versal set of basic needs, there is not one standard basic-needs strategy. There is the basic-needs approach which must be translated into $a$ basic-needs strategy appropri ate to requirements and resources of each particular country. How this can be transformed into action has been the subject of much debate both within and outside the ILO. The purpose of the remainder of this paper is to offer two novel ways that can be used to operationalise the concept of basic needs.

\section{BASIC-NEEDS ACTIVITIES}

At the request of the governments, the ILO has conducted detailed, although exploratory, studies of the implications of implementing a basic-needs strategy in Bangladesh, Guyana, Kenya, the Philippines, Portugal, Sierra Leone, Somalia, Swaziland, Tanzania, Thailand and Zambia. The approach in each of these studies has been different, a major reason being that data available have varied from one country to another. An interesting and useful approach was developed in a recent planning exercise in Kenya. Based upon a set of criteria, an attempt was made to identify what were termed "basic needs activities". In the case of Kenya, the criteria were that an activity

(1) raises incomes of the target groups through employment creation, asset redistribution and productivity-enhancing measures to reach a target income over a specified period;

(2) makes a direct contribution to the achievement of the targets established in respect of core basic needs such as nutrition, health, education, housing and water;

(3) increases production of other basic goods and services purchased by low-income groups from their disposable incomes and by public sector and communal agencies; and

(4) enhances decentralisation, participation and self-reliance.
In addition to these criteria, basic needs activities should, to the extent possible,

(a) use simple equipment;

(b) have relatively small capital cost;

(c) require low skill levels; and

(d) use local materials [1]

Unavoidably, not all projects can meet all the criteria, particularly (a) to (d). Furthermore, these criteria were developed for the particular situation of Kenya, and other countries may require a different or an expanded set.

An important point to remember is that there exist major forward and backward linkages with all basic-needs activities. An expansion of low-cost housing programmes will lead to increased demand for skilled and unskilled labour as well as locally produced housing materials. Increased emphasis on rural road building will increase demand for simple implements. The increased employment resulting from such efforts will boost incomes, thus leading to greater demand for basic-needs goods and services. This also may give impetus to more informal-sector activities.

In a move towards a strategy of basic-needs activities, certain quantitative and qualitative information is required. To a certain extent the approach to planning and the techniques used will dictate data requirements. The data are needed to obtain estimates of required resources, as well as for monitoring progress and assessing the over-all impact of the projects. The importance of simplicity in the tech niques chosen cannot be overemphasised, since sophisticated data are not generally available in developing countries. Analytically speaking, less sophisticated techniques may be inferior, yet operational feasibility may dictate that techniques, such as input-output tables, be avoided. In the case of Kenya, the following types of data were suggested:
(a) nature of output;
(b) value of output;
(c) capital expenditure;
(d) recurrent expenditure;
(e) local costs;
(f) foreign exchange costs;
(g) labour requirements by skill categories;
(h) raw materials requirements;
(i) tools and equipment; and
(j) value added by wages and surplus.

Such information will need to be supplemented with information of a more qualitative nature which indicates decentralisation, participation and self-reliance. Possible candidates include local decision-making power, size of activity, ownership and control of implementation. 
Based upon such considerations, major basic-needs activities in Kenya ${ }^{1}$ were identified as:

(1) The Rural Access Roads Programme. The main objectives are to improve transport and other links to relatively inaccessible parts of rural areas utilising labour-intensive techniques, operating on a small scale with stress on decentralisation and local participation in selection of sites and in repair and maintenance. It is hoped thereby to stimulate rural development and provide employment opportunities to low-income groups in rural areas, especially during slack seasons;

(2) The Rural Works Programme. The basic objectives are employment creation for poor rural families, creation of economically useful assets and increased and decentralised participation in the planning process;

(3) The Integrated Agricultural Development Programme. Its major objective is to reach the thus far bypassed poor small holders to increase agricultural production of food crops for domestic consumption;

(4) Promotion of the Informal Sector. This sector is characterised by ease of entry, reliance on indigenous resources, family ownership of enterprise, small-scale operation, labour-intensive adapted technology, skills acquired informally and unregulated and competitive markets. The sector generates much employment and produces a wide range of goods and services consumed by low-income groups. The aim is to reduce harassment by public authorities, improve premises, increase access to credit and reduce licensing problems;

(5) Site and Service Housing Schemes. Basic infrastructural work is undertaken by public authorities while the building of the house is left to plot-owners. The building of the house can be done by the plot-owners. The building of the house can be done by the plot-owner himself, on a cooperative basis with other plot-owners or through sub-contracting to private small builders. The major characteristics of the programme are highly labour-intensive techniques, relatively simple, low-cost tools and local materials;

(6) The Rural Water Supply Programme. Beside contributing directly to the achievement of a major basic need, this programme can be viewed as one which raises productivity by the supply of safe water. To the extent possible, the programme will be undertaken using self-help groups;

(7) The Universal Adult Literacy Programme. This programme aims at increasing the productivity of a particularly deprived group as well as at making a contribution to the satisfaction of another major basic need. It is also to

${ }^{1}$ Only the major justifications from a basic-needs activity viewpoint are given here. For a fuller discussion, see [1, pp. $98-133]$. operate within a decentralised, participatory and self-reliant framework; and

(8) The Rural Health Development Project. The aim of this project is to cut the incidence of preventable health problems by one-half by 1984. The project is based upon conventional as well as the primary health-care approach. This will increase worker productivity, create employment and be based on community participation in decision-making and implementation.

This rather short exposition conceals many important points which will need to be taken into account in planning. Resource requirements need to be considered. There are also the organisational, administrative and training needs that need to be fulfilled. Finally, proper implementation will require monitoring and evaluation of the programmes and projects so that, should problems arise, an attempt can be made to rectify them before too much harm is done to objective achievement. The importance of a basic-needs activity approach to planning stems from its methodological approach to the economic as well as the social objectives of development. While such an approach is a considerable advance over more conventional ones, there will still be poor who will not be reached. With time and experience, a larger effort can be made in the future to include them in the distribution of the benefits.

\section{PRODUCT PATH ANALYSIS}

An alternative, although not necessarily distinct, way of operationalising the concept of basic needs is through the use of product path analysis. ${ }^{2}$ This tool allows one to disaggregate various development programmes so as to ascertain the extent to which they contribute to meeting the requirements of diverse target groups. The analyses undertaken with product path analysis are essentially the flow of certain inputs into outputs.

The first step in the process is to identify precisely the components of basic needs. This means that it is not sufficient to say that food is a basic need, but rather what types of food take priority. Thus, for example, one may find that pulse crops are a consumption good of the poor in a subsistence economy. It is then necessary to determine what the requirements of the particular good or service are based upon a "rational budget" for a representative poor household. Various different conditions will determine what is rational, e.g. legitimacy, social acceptance, reasonableness with respect to possible output and physiological norms. The rational budget requirements which result can then be compared with current consumption habits. The result is either shortfall or overconsumption that forms the point of departure for planning with product path analysis.

${ }^{2}$ Much of this section is based upon [3] 
The use of product path analysis is best illustrated by way of example. A rather less complicated example is that of irrigation. First, it is necessary to analyse the expected distribution of the water supplied by the project over various different types of output. For simplicity, assume that one-half of the water supplied will be used for pulse crops and the other half for maize production. Low-income groups account for 40 percent of the pulse market and 10 percent of the maize market. Assume further that pulse crops are a requirement for the lower classes while maize is not Thus, 25 percent of the water supplied through the irrigation project is important in meeting the demand of the lower class $((.40 \times .50)+(.10 \times .50))$. This figure is made up of the requirements component, 20 percent, and that of non-required maize, 5 percent.

It should be clear from this simplified example that product path analysis has numerous uses in planning. Indeed, the analysis has been applied in various developing countries to power plants, hospitals, steel factories and cement works, among others. One can envisage that, with some modification and imagination, this tool could also be applied to an analysis of policies such as rural-development strategies aimed at small farmers or wage policy and industrialization. A slightly more sophisticated example of product path analysis is given in Table 1.

The project under consideration in Table 1 is a fertilizer plant. The fertilizer produced will be channeled into pulse, cotton and maize production in the proportions indicated in column 2. These intermediate outputs will be transformed into the final consumer goods as given in column 3. The next column is the distribution of fertilizer among the various final consumption goods. The figures in this column are derived by multiplying the appropriate proportions in columns 2 and 3. The market share of the low-income target group in each of the various outputs (column 5) must be obtained from other sources. This might be, for example, an existing household income and expenditure survey. Given these figures, it is possible to estimate the demand of the target group for the output of this project. Column 6 is obtained by the multiplication of the fertilizer distribution and the market share. The sum of column 6, i.e. 32.0, implies that that percentage of total output flows to the target group. It should be noted that the complement to 100.0 , i.e. 68.0 , is the amount of output which will flow to the non-targeted group. Finally, column 6 is compared with column 7. The latter column is derived from the "rational budget" alluded to earlier and the figures represent the needs of the target group for each of the outputs. From the comparison of the columns, one would conclude that the fertilizer plant in question is important for basic-needs satisfaction. Indeed, for those components which have a non-zero requirement, the project output meets or surpasses them in the demand fulfilled.

Product path analysis is, thus, an attempt to empirically reconstruct the flow of inputs into outputs with a view to their efficacy in fulfilling the requirements of basic needs. To this extent, it seems to be a tool well-suited to providing answers to

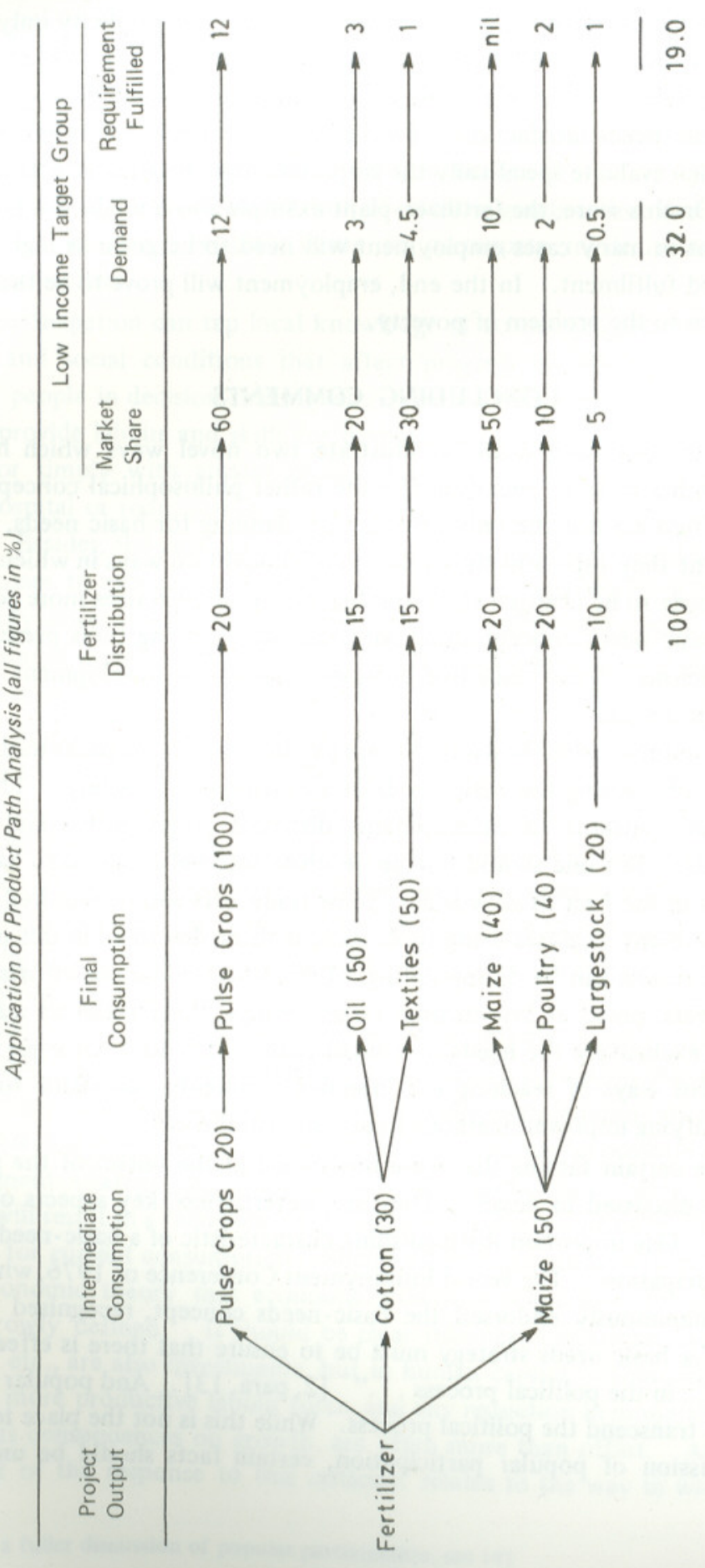


social development questions as well as economic ones. Its simplicity only serves to increase its attractiveness. Aside from its use in identifying priorities, project path analysis can be used to evaluate existing programmes and policies vis-a-vis their contribution to basic-needs satisfaction. Parallel to such efforts, others will need to be undertaken which evaluate specifically the employment-generating effects of projects and policies. On this score, the fertilizer - plant example above might not fare so well. It is certain that in many cases employment will need to be given as high a priority as physical-need fulfilment. In the end, employment will prove to be the only sustainable solution to the problem of poverty.

\section{CONCLUDING COMMENTS}

An attempt has been made to illustrate two novel ways which have been applied to planning so as to operationalise the rather philosophical concept of basic needs. These two are not the only attempts at planning for basic needs, but to an important extent they represent the evolution of thought on ways in which the planning process needs to be changed so as to integrate social objectives more concretely. As such, the basic-needs concept along with the two planning tools presented here represents criticisms of the main-line economic theory of development that have been in vogue in the past.

Certain countries have shown that there can be a variety of paths leading to the same objective of meeting the basic needs of all members of society. These paths involve different patterns of development, different policy mixes and different political systems. But one should not be deceived into believing that a basic-needs strategy results in the best of all worlds. Some trade-offs will be required. Indeed, the outcome of many analyses using tools such as those described in this paper have found that the results can be disappointing. Even where conscious efforts are made to design projects aimed at low-income target groups, these activities may end up serving almost exclusively the needs of a small elite. This does not argue for a stop in the search for ways of reaching the intended recipients, but rather to intensify efforts at identifying improved methods to accomplish the task.

There are certain factors that were mentioned at the outset of the paper but have not been discussed in detail. They are, nevertheless, key aspects of a basicneeds strategy. One important distinguishing characteristic of a basic-needs strategy is popular participation. The World Employment Conference of 1976, which it will be recalled, unanimously endorsed the basic-needs concept, recognised that "the main thrust of a basic needs strategy must be to ensure that there is effective mass participation ... in the political process ..." [2, para. 13]. And popular participation must also transcend the political process. While this is not the place to enter an in-depth discussion of popular participation, certain facts should be understood.
Grass-roots participation can contribute to improvements in living standards and meeting basic needs in four ways:

(1) by helping to identify basic needs;

(2) by mobilising resources to meet basic needs;

(3) by improving the distribution of essential goods and services; and

(4) by satisfying people's desire to participate in decisions which affect their lives.

Popular participation can tap local knowledge of economic opportunities and of the physical and social conditions that affect progress of development programmes. Involving people in decision-making may directly affect employment by encouraging them to provide labour and skills for development programmes voluntarily, or more cheaply or simply with greater productivity. Assets created in this way, e.g. a school, hospital or road, can in turn contribute to the improvement of employment directly. Besides, the satisfaction of basic needs requires more than the mobilisation of the masses to execute policies and programmes emanating from decisions which are basically bureaucratic in origin. It depends upon mechanisms that encourage participation in decision-making itself, together with a process by which the poor are organised or organise themselves to ensure that the decisions taken are in their interest. In a word, popular participation must be popular, a free and spontaneous expression of the people's will. However perfect the institutions through which it is exercised, participation that is subject to official control and manipulation, that is a mere front for authoritarian dirigisme or coercion, is not true participation at all. Irrespective of the tools or mechanisms which are employed in arriving at a basicneeds strategy, ignoring the wishes of the people and excluding them from the decision-making and implementation process, will make the effort only a half-success even if physical needs are met. ${ }^{3}$

Finally, a few words will be said about economic growth. Considering the overwhelming rhetorical commitment to the need to improve the welfare of the poor, the basic-needs concept has received a surprising amount of criticism, even from unexpected quarters. Criticism primarily concerns the possible effects of such a development strategy on economic growth. Such critics often argue that the approach will result in a reduction in savings and productive investment, thus sacrificing future for current consumption. Such a viewpoint emanates from the somewhat archaic economic theory that economic growth is primarily a function of investment, narrowly defined. It should be clear that better nutrition, housing, health, education, etc., are also investments, but in human capital. These investments will result in a more productive labour force, and any reduction in monetary investment, whatever its consequences on growth, are often more than offset. Another important aspect of the response to this criticism relates to the way in which growth is 
perceived. Currently accepted measurements of economic growth show no distinction with respect to what is produced or who receives it. Whether production is of guns or of butter or whether output flows to the rich elite or to the rural poor is of little concern. Just as the basic-needs approach is aimed at turning conventional planning on its head, so too must the concept of economic growth be viewed from a different perspective. The purpose of growth is an improvement in the welfare of all the people, and when viewed from this point, any hypothesised trade-off between basic needs and growth may turn out to be a mirage. When properly planned and implemented, economic growth will be the result rather than the goal of a basicneeds strategy.

\section{REFERENCES}

1. Ghai, Dharam, Martin Godfrey and Franklyn Lisk. Planning for Basic Needs in Kenya. Geneva: ILO. 1979.

2. ILO. Meeting Basic Needs : Strategies for Eradicating Mass Poverty and Unemployment. Geneva. 1977.

3. Schwefel, Detlef. Basic Needs Planning and Evaluation. Berlin : German Development Institute. 1979.

4. Szal, Richard J. (ed.). "Popular Participation, Employment and the Satisfaction of Basic Needs". International Labour Review. Vol. 118, No. 1. JanuaryFebruary 1979. ["This paper is a summary of work undertaken within the Economic and Social Policy Synthesis Unit of the Employment and Development Department of the ILO as a follow -up to the World Employment Conference held in 1976."] 